\title{
Human islet amyloid polypeptide at pharmacological levels inhibits insulin and phorbol ester-stimulated glucose transport in in vitro incubated human muscle strips
}

\author{
J. R. Zierath ${ }^{1}$, D. Galuska ${ }^{1}$, Å. Engström ${ }^{2}$, K.H.Johnson ${ }^{5}$, C. Betsholtz ${ }^{3}$, P. Westermark ${ }^{4}$ and H. Wallberg-Henriksson $^{1}$ \\ ${ }^{1}$ Department of Clinical Physiology, Karolinska Hospital, Stockholm, ${ }^{2}$ Department of Immunology, ${ }^{3}$ Department of Pathology, \\ University of Uppsala, Uppsala, ${ }^{4}$ Department of Pathology, University Hospital, Linköping, Sweden, and ${ }^{5}$ Department of Veterinary \\ Pathobiology, College of Veterinary Medicine, University of Minnesota, St. Paul, Minnesota, USA
}

\begin{abstract}
Summary. Human islet amyloid polypeptide, at concentrations of $1-100 \mathrm{nmol} / \mathrm{l}$, has been demonstrated to inhibit the insulin-stimulated increase in rat muscle glycogen content. However, at physiological concentrations $(1-10 \mathrm{pmol} / \mathrm{l})$ of islet amyloid polypeptide, no effects have been reported. We tested the effect of a wide range of concentrations of human islet amyloid polypeptide on insulin- and phorbol esterstimulated 3-0-methylglucose transport in in vitro incubated human skeletal muscle. Muscle specimens from the quadriceps femoris muscle were obtained from 23 healthy subjects with the use of a newly-developed open muscle biopsy technique. Human islet amyloid polypeptide at a concentration of $100 \mathrm{nmol} / \mathrm{l}$ had no effect on basal glucose transport, but inhibited the stimulatory effect of a maximal insulin concentration $(1000 \mu \mathrm{U} / \mathrm{ml})$ by $69 \%(p<0.001)$. The presence of human islet amyloid polypeptide at 1,10 and $100 \mathrm{nmol} / 1 \mathrm{de}-$ creased the effect of $100 \mu \mathrm{U} / \mathrm{ml}$ of insulin on glucose transport by $61 \%(p<0.05), 78 \%(p<0.05)$ and $76 \%(p<0.05)$,
\end{abstract}

respectively. Similarly, human islet amyloid polypeptide at a concentration of $10 \mathrm{nmol} / 1$ inhibited phorbol ester-stimulated glucose transport by $100 \%(p<0.05)$. The inhibitory effects of human islet amyloid polypeptide on glucose transport were present in the muscle strips despite no net changes in glycogen content. Human islet amyloid polypeptide at 10 and $100 \mathrm{pmol} / \mathrm{l}$ had no effect on the rate of insulin-stimulated glucose transport. In conclusion, pharmacological concentrations of human islet amyloid polypeptide inhibit insulinas well as phorbol ester-stimulated glucose transport in human skeletal muscle, while physiological concentrations do not exert an inhibitory effect. Furthermore, these results suggest that the inhibitory effect of human islet amyloid polypeptide on glucose transport is located at a point distal to the insulin binding process.

Key words: 3-0-methylglucose, glycogen, insulin, lactate, skeletal muscle, phorbol esters.
The presence of amyloid deposits in the islets of Langerhans of Type 2 (non-insulin-dependent) diabetic patients has been well documented $[1,2]$. The major constituent of amyloid is a 37 amino acid polypeptide termed islet amyloid polypeptide (IAPP) [2], which has also been identified as diabetes-associated peptide [3] or amylin [4]. In rat stripped soleus muscles, hIAPP at concentrations between $1-120 \mathrm{nmol} / 1$ decreased basal as well as insulinstimulated glycogen synthesis $[4,5]$. Furthermore, during euglycaemic clamp studies in rats [6] and dogs [7], infusions of hIAPP significantly decreased the rate of insulinmediated glucose disposal. In the latter studies, the peripheral concentrations of infused IAPP were not determined.

In rat skeletal muscle, rat IAPP (rIAPP) at concentrations of 10 and $100 \mathrm{nmol} / 1$ [8], as well as IAPP (species undefined by authors) at $1 \mu \mathrm{mol} / \mathrm{l}$ [9] decreased insulin-stimulated 2-deoxyglucose transport. Conversely, $10 \mathrm{nmol} / 1$ of hIAPP did not affect insulin-stimulated rates of 2-deoxyglucose transport in rat soleus muscles [10]. When using the non-metabolizable glucose analogue 3-0methylglucose, no effect of rIAPP (1-100 nmol/l) was evident in isolated rat soleus muscles [8]. Thus, reports concerning the effect of IAPP on the glucose transport process in rat skeletal muscle are conflicting. In man, an infusion of synthetic hIAPP had no effect on i.v. glucose tolerance in healthy control subjects [11]. The effect of IAPP directly on human skeletal muscle remains to be studied. Furthermore, no effects have been reported at physiological concentrations of IAPP. The aim of the present study was to investigate the effect of physiological and pharmacological concentrations of synthetic hIAPP on the cellular glucose transport process in human skeletal muscle. For this purpose, we employed an open muscle biopsy technique to obtain human muscle specimens suitable for in vitro incubations similar to the method reported by Dohm and co-workers [12]. 


\section{Subjects and methods}

\section{Subjects}

Muscle specimens from the vastus lateralis portion of the quadriceps femoris muscle were obtained from 23 healthy subjects ( 16 male and 7 female). None of the subjects were under any medication. These subjects were moderately engaged in physical activity 2-3 times per week. The study protocol was reviewed and approved by the ethical committee of the Karolinska Institute. The nature, purpose, and possible risks of the study were carefully explained to each subject before giving their consent to participate.

\section{Open muscle biopsy procedure}

The subjects reported to the laboratory following an overnight fast. Local anaesthesia (Mepivakain chlorid $5 \mathrm{mg} / \mathrm{ml}$ ) was administered and a 4-cm incision was made $15 \mathrm{~cm}$ above the proximal border of the patella and the skin and fascia were reflected to expose the intact muscle fibres of the vastus lateralis portion of the quadriceps femoris muscle. The muscle specimen was clamped at resting length in vivo, excised, and immediately transferred to a beaker which contained oxygenated Krebs-Henseleit bicarbonate buffer [13], $5 \mathrm{mmol} / 1$ HEPES (N-2-Hydroxyethylpiperazine-N'-2-ethanesulphonic acid), $0.1 \%$ bovine serum albumin (KHB) and was further supplemented with $38 \mathrm{mmol} / \mathrm{l}$ mannitol and $2 \mathrm{mmol} / \mathrm{l}$ pyruvate and transported to the laboratory $(<2 \mathrm{~min})$. Thereafter, muscle strips weighing $18.8 \pm 0.1 \mathrm{mg}$ (range $7.35-33.15 \mathrm{mg}$ ) were dissected free, mounted on plexi-glass clamps $(0.9 \mathrm{~cm}$ wide $)$ and removed from the tissue specimen as described previously [12]. From one muscle specimen, 5-16 smaller muscle strips were obtained.

\section{Incubation medium}

All solutions were prepared daily from a KHB stock ( $\mathrm{pH} 7.4$ ), which was pre-gassed with $95 \% \mathrm{O}_{2} / 5 \% \mathrm{CO}_{2}$. Three types of media were used: 1) medium for pre-exposure, 2) pre-incubation medium, and 3) radioactive medium for 3-0-methylglucose transport measurements. The pre-exposure medium for each experiment contained KHB supplemented with $38 \mathrm{mmol} / 1$ mannitol, $2 \mathrm{mmol} / \mathrm{l}$ pyruvate and hIAPP at concentrations stated in the figures and tables. The pre-incuabtion medium contained KHB, $40 \mathrm{mmol} / 1$ mannitol, insulin $(0,100$, and $1000 \mu \mathrm{U} / \mathrm{ml})$ and hIAPP at the same concentration used in the pre-exposure medium. The radioactive medium for 3-0methylglucose transport measurements consisted of KHB containing $5 \mathrm{mmol} / 13-0-^{3}[\mathrm{H}]$ methylglucose $(437 \mu \mathrm{Ci} / \mathrm{mmol}), 35 \mathrm{mmol} / 1$ ${ }^{14}[\mathrm{C}]$ mannitol $(8 \mu \mathrm{Ci} / \mathrm{mmol})$, and insulin and hIAPP at the same concentrations used in the pre-incubation period. The mannitol concentration of the different media was varied between 35 and $40 \mathrm{mmol} / \mathrm{l}$ to keep osmolarity constant in the presence or absence of pyruvate or 3-0-methylglucose. The hIAPP was dissolved in $0.1 \mathrm{~mol} / \mathrm{l}$ acetic acid immediately before being added to the media. An equal volume of acetic acid was added to all media not containing hIAPP.

\section{In vitro muscle strip incubations}

Immediately following tissue preparation, the muscle strips were placed in individual stoppered flasks in a shaking incubator (110 times/min) maintained at $35^{\circ} \mathrm{C}$. The muscle strips were allowed to recover for $15 \mathrm{~min}$ in $\mathrm{KHB}$ containing $2 \mathrm{mmol} / \mathrm{l}$ pyruvate and $38 \mathrm{mmol} / \mathrm{l}$ mannitol. Thereafter, the muscle strips were transferred to pre-exposure media for $15 \mathrm{~min}$ and then transferred to pre-incubation media for a $30-\mathrm{min}$ incubation period. Following this procedure, the muscles were incubated at $35^{\circ} \mathrm{C}$ in $2 \mathrm{ml}$ of radioactive medium for $30 \mathrm{~min}$. The muscles were then freeze-clamped with aluminium tongs cooled to the temperature of liquid $\mathrm{N}_{2}$, weighed, homogenized in $1 \mathrm{ml}$ of $10 \%$ trichloroacetic acid, and analysed for content of ${ }^{3}[\mathrm{H}]$ and ${ }^{14}[\mathrm{C}]$. A detailed description of the analytical procedure has been given elsewhere [14].

\section{Islet amyloid polypeptide}

C-terminally amidated human IAPP was assembled by the solidphase procedure [15] using an Applied Biosystems 430 A synthesizer on p-methylbenzhydrylamine resin. tert-Butyloxycarbonyl amino acids were coupled as symmetrical anhydrids in two-fold molar excess, except for $\mathrm{Arg}(\mathrm{Tos})$, Asn and Gln, which were coupled as 1-hydroxybenzotriazole esters. Double couplings followed by capping with acetic anhydride were used throughout the synthesis. Sidechain-protecting groups were: $\mathrm{Bzl}$ for Ser and $\mathrm{Thr}, \mathrm{Br}-\mathrm{Z}$ for $\mathrm{Tyr}, \mathrm{Me}-$ $\mathrm{Bzl}$ for Cys, Dnp for His, Tos for Arg and Cl-z for Lys.

The peptide resin $(1 \mathrm{~g})$ was treated overnight with $0.5 \mathrm{~mol} / \mathrm{l}$ thiophenol/dimethylformamide for removing of Dnp groups, and the peptide was liberated from the resin by reaction with hydrogen Fluoride (HF) $(8 \mathrm{ml})$ in the presence of anisole $(1 \mathrm{ml})$, p-thiocresol $(0.2 \mathrm{ml})$ and dimethyl sulphide $(1 \mathrm{ml})$. The resin obtained after removal of HF in vacuo was washed with ether and the peptide was extracted with total fatty acids and precipitated with ether. For formation of the disulphide, the peptide $(25 \mathrm{mg})$ was dissolved in $0.5 \mathrm{~mol} / 1 \mathrm{Tris}-\mathrm{HCl}, 6 \mathrm{~mol} / 1$ guanidine- $\mathrm{HCl}, 1 \% \beta$-mercaptoethanol and incubated under nitrogen for $2 \mathrm{~h}$ at $37^{\circ} \mathrm{C}$. The reduced material was desalted on Sephadex G-25 using $30 \%$ acetic acid as eluent. The peptide-containing fraction $(3 \mathrm{ml})$ was diluted to $100 \mathrm{ml}$ with water, and the $\mathrm{pH}$ was adjusted to 8.3 with ammonia. The peptide solution was lyophilized after $5 \mathrm{~h}$. Final purification was performed by reversed phase chromatography on a Nucleosil C18 column eluted with a gradient of acetonitrile in water containing $0.1 \%$ total fatty acids.

Plasma desorbtion mass spectrometry [16] on a Biolon 20 instrument showed the expected molecular mass. The absence of free sulphydryl groups in the oxidased material were determined by mass analysis after treatment with 4 -vinylpyridine. The increase in molecular mass obtained by treatment of reduced IAPP with 4-vinylpyridine was not detected after treatment of the oxidased material.

\section{Biochemical assays}

Muscle biopsies which were excised during surgery, and incubated muscle strips were rapidly freeze-clamped with aluminium tongs cooled to the temperature of liquid nitrogen, and stored at $-80^{\circ} \mathrm{C}$ for subsequent preparation and metabolic analysis as described earlier [14]. ATP, phosphocreatine ( $\mathrm{PCr}$ ), lactate, and glycogen were analysed fluorometrically according to Lowry and Passonneau [17], with slight modifications as indicated by Wallberg-Henriksson et al. [14]. Glycogen was assessed for the extract and the pellet, and the result was combined to indicate the glycogen concentration of the muscle [17]. In a pilot study, basal pre-incubation media was analysed for lactate dehydrogenase activity (LD) [18] following $1 \mathrm{~h}$ of muscle incubation. Blood samples were obtained from all subjects at the time of the muscle excision and were analysed for fasting serum glucose (Beckman Instrument Inc., Fullerton, Calif., USA), and serum immunoreactive insulin (Phadeseph Insulin RIA method Pharmacia, Uppsala, Sweden). The lower limit of sensitivity of the insulin assay was $3.0 \mu \mathrm{U} / \mathrm{ml}$ of insulin.

\section{Chemicals}

All chemicals were obtained from Sigma Chemical Company (St. Louis, Mo., USA) and enzymes were obtained from Boehringer Mannheim GmbH Biochemica (Mannheim, FRG). The BSA obtained from Sigma was essentially fatty acid free. The insulin (Actrapid) was a product of Novo-Nordisk A/S, (Copenhagen, Denmark). The $4 \beta$-phorbol $12 \beta$-myristate $13 \alpha$-acetate (PMA) was purchased from Pharmacia. All radioactive products were obtained from New England Nuclear (Boston, Mass., USA). 
Table 1. Metabolic characteristics of directly frozen biopsies and incubated muscle strips

\begin{tabular}{lccc}
\hline & $n$ & $\begin{array}{l}\text { Directly frozen } \\
\text { biopsy }\end{array}$ & $\begin{array}{l}\text { Incubated } \\
\text { muscle strips }\end{array}$ \\
\cline { 2 - 4 } & & $\left(\mathrm{mmol} \cdot \mathrm{kg}^{\mathrm{a}} \cdot\right.$ dry weight $\left.^{-1}\right)$ \\
\hline ATP & 9 & $30.4 \pm 1.5$ & $25.2 \pm 1.6^{\mathrm{b}}$ \\
PCr & 9 & $71.9 \pm 2.1$ & $53.9 \pm 5.6^{\mathrm{b}}$ \\
Glycogen & 9 & $369.2 \pm 36.2$ & $319.2 \pm 25.0$ \\
\hline
\end{tabular}

Values are expressed as mean $\pm \mathrm{SEM}$.

${ }^{a}$ Incubated in the basal state; ${ }^{b} p<0.05$ vs directly frozen biopsy. PCr, phosphocreatine

Table 2. Effect of islet amyloid polypeptide (IAPP) on basal and insulin stimulated 3-0-methylglucose transport

\begin{tabular}{llll}
\hline Insulin & $n$ & \multicolumn{2}{l}{$\begin{array}{l}\text { 3-0-methylglucose transport } \\
\left(\mu \mathrm{mol} \cdot \mathrm{ml}^{-1} \cdot \mathrm{h}^{-1}\right)\end{array}$} \\
\cline { 2 - 4 } & & No hIAPP & hIAPP $10^{-7} \mathrm{~mol} / \mathrm{l}$ \\
\hline 0 & 6 & $0.46 \pm 0.08$ & $0.52 \pm 0.09$ \\
$100 \mu \mathrm{U} / \mathrm{ml}$ & 5 & $0.87 \pm 0.13$ & $0.45 \pm 0.13^{\mathrm{a}}$ \\
$1000 \mu \mathrm{U} / \mathrm{ml}$ & 5 & $1.03 \pm 0.12$ & $0.64 \pm 0.11^{\mathrm{b}}$ \\
\hline
\end{tabular}

Values are expressed per $\mathrm{ml}$ of intracellular water. Values are means \pm SEM.

${ }^{\mathrm{a}} p<0.01$ vs no hIAPP; ${ }^{\mathrm{b}} p<0.001$ vs no hIAPP

\section{Statistical analysis}

The statistical significance of the differences between muscle strips incubated in the presence or absence of hIAPP as well as between directly frozen muscle biopsy specimens and incubated muscle strips (metabolic levels) was determined by Student's paired $t$-test. The statistical significance of the difference between the various concentrations of hIAPP was analysed by one-way analysis of variance (ANOVA), and differences between the concentrations were identified by the Newman-Keuls post hoc test. A significant level of $p<0.05$ has been applied. Data are reported as mean \pm SEM.

\section{Results}

\section{Subject characteristics}

The subjects participating in the present investigation were $27 \pm 1$ years of age, weighed $69.2 \pm 0.5 \mathrm{~kg}$, were $178 \pm 2 \mathrm{~cm}$ in height, and had a body mass index of $22.7 \pm 0.5 \mathrm{~kg} / \mathrm{m}^{2}$. Serum glucose concentration at the time of the muscle excision was $4.0 \pm 0.2 \mathrm{mmol} / \mathrm{l}$ and the serum insulin concentration was $10.7 \pm 0.6 \mu \mathrm{U} / \mathrm{ml}$.

\section{Viability of muscle strip preparation}

To assess the viability of the muscle strip preparation, high energy phosphate and glycogen levels were measured in biopsies which were frozen during surgery and in muscle strips obtained following $90 \mathrm{~min}$ of in vitro incubation (Table 1). The in vitro incubation procedure resulted in slight decreases in ATP and PCr levels, whereas the glycogen content remained unchanged (Table 1).

In a pilot study, LD activity was analysed in basal preincubation media from muscle strips incubated for $1 \mathrm{~h}$. To account for any LD contribution from the outer ends of
J.R.Zierath et al.: Human IAPP decreases muscle glucose transport

the muscle strip a clamp with two exposed muscle ends was incubated under the conditions described above. This value represented LD activity which resulted from the loose tissue at the outer edges of the clamp (tissue blank). Lactate dehydrogenase activity did not differ between media exposed to a muscle strip $(3.70 \pm 0.7 \mu \mathrm{kat} / 1, n=6)$ and the tissue blank ( $3.57 \pm 0.3 \mu \mathrm{kat} / \mathrm{l}, n=14)$ indicating that the muscle strips did not release significant amounts of $\mathrm{LD}$ during the incubation period.

\section{Effect of hIAPP on insulin-stimulated glucose transport}

In the first series of experiments, hIAPP at a concentration of $100 \mathrm{nmol} / 1$ was tested (Table 2). In the presence of hIAPP, basal 3-0-methylglucose transport was unaltered, whereas the stimulatory effect of insulin at concentrations of 100 and $1000 \mu \mathrm{U} / \mathrm{ml}$ decreased 3-0-methylglucose transport by $100 \%(p<0.01)$ and by $69 \%(p<0.001)$, respectively. In the second series of experiments, a dose-response curve for the effect of hIAPP on insulin-stimulated $(100 \mu \mathrm{U} / \mathrm{ml})$ glucose transport was investigated (Fig. 1). Insulin increased 3-0-methylglucose transport from $0.46 \pm 0.08$ to $1.01 \pm 0.09 \mu \mathrm{mol} \cdot \mathrm{ml}^{-1} \cdot \mathrm{h}^{-1}$. Human IAPP at 10 and $100 \mathrm{pmol} / \mathrm{l}$ did not alter this insulin effect on 3-0methylglucose transport. However, 1,10 and $100 \mathrm{nmol} / 1$ of hIAPP decreased the insulin-stimulated glucose transport by $61 \%(p<0.05), 78 \%(p<0.05)$ and $76 \%(p<0.05)$, respectively (Fig. 1).

\section{Effect of hIAPP on phorbol ester-stimulated glucose transport}

Insulin-stimulated glucose transport may be inhibited by hIAPP directly at one or several step(s) in the metabolism of glucose. The possibility remains that hIAPP inhibits the glucose transport process by blocking the binding of in-

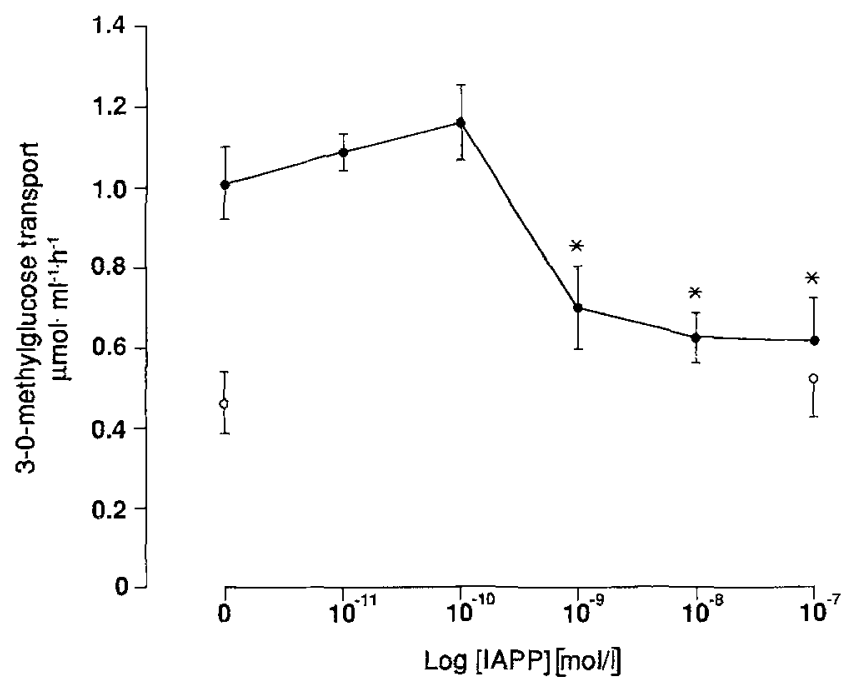

Fig.1. Effect of increasing concentrations of human islet amyloid polypeptide (hIAPP) on insulin-stimulated $(100 \mu \mathrm{U} / \mathrm{ml})(\mathbf{0})$ and basal (O) 3-0-methylglucose transport in incubated muscle strips. Results are expressed per $\mathrm{ml}$ of intracellular water. Values are means \pm SEM. Each point represents $4-9$ subjects. ${ }^{*} p<0.05$ vs basal conditions 


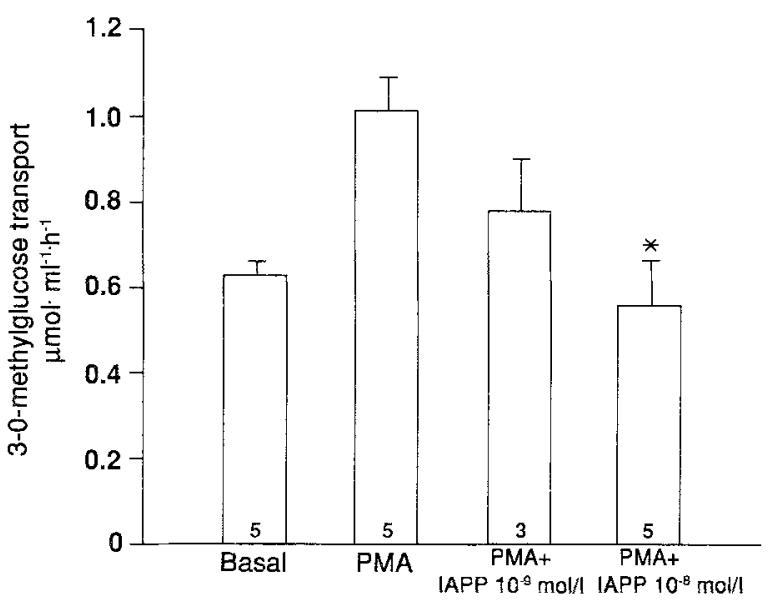

Fig. 2. Effect of human islet amyloid polypeptide (hIAPP) on phorbol ester (PMA)-stimulated 3-0-methylglucose transport in incubated human muscle strips. Results are expressed per ml of intracellular water. Values are means \pm SEM. Sample size is indicated in each bar. * $p<0.05$ vs PMA with no further addition of IAPP

sulin to its specific receptor. To test the latter hypothesis, the effect of hIAPP on phorbol ester-stimulated glucose transport was investigated. Phorbol esters (PMA) are believed to affect the glucose transport system distal to the insulin binding, possibly via activation of protein kinase $\mathrm{C}$ [19]. The presence of $0.25 \mathrm{mg} / \mathrm{ml}$ of PMA in the incubation media increased 3-0-methylglucose from $0.63 \pm 0.04$ to $1.00 \pm 0.01 \mu \mathrm{mol} \cdot \mathrm{ml}^{-1} \cdot \mathrm{h}^{-1}$ (Fig. 2). An addition of $1 \mathrm{nmol} / \mathrm{l} \mathrm{hIAPP}$ to the incubation media had no significant inhibitory effect on PMA-stimulated glucose transport (NS). The effect of PMA decreased by $100 \%(p<0.05)$ when $10 \mathrm{nmol} / 1$ of hIAPP was added to the incubation media.

\section{Glycogen and lactate levels}

Glycogen and lactate levels were analysed in muscle strips exposed to either insulin plus 0,1 and $100 \mathrm{nmol} / \mathrm{l}$ of hIAPP or to PMA and 0,1 and $10 \mathrm{nmol} / 1$ of hIAPP. No significant changes in the levels of glycogen and lactate occurred during the $75 \mathrm{~min}$ of hIAPP exposure (Table 3 ).

Table 3. Glycogen and lactate concentrations in incubated muscle strips

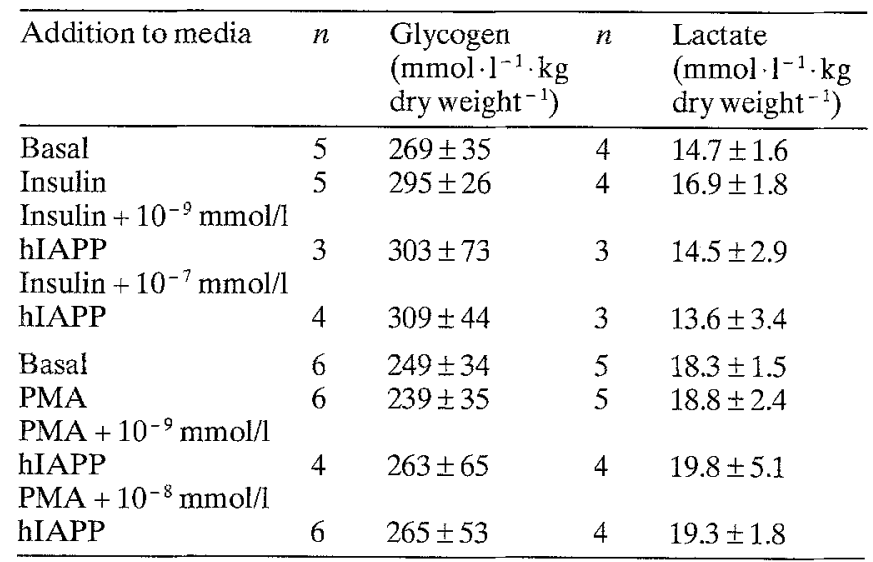

Values are expressed as mean \pm SEM. PMA, phorbol esters

\section{Discussion}

Islet amyloid polypeptide (IAPP) in pharmacological concentrations has a catabolic effect on glycogen levels in rat skeletal muscle $[3,4,8,10]$. Our report presents additional evidence, which demonstrates that synthetic human amyloid polypeptide, hIAPP, significantly inhibits insulinstimulated glucose transport in incubated human skeletal muscle. Using a recently developed technique to obtain human skeletal muscle for in vitro incubation, we found that pharmacological concentrations of hIAPP $(1-100$ $\mathrm{nmol} / \mathrm{l}$ ) inhibited the insulin-stimulated increase in the 3-0-methylglucose transport, but physiological concentrations $(10-100 \mathrm{pmol} / \mathrm{l})$ did not alter the rate of glucose transport. Since 3-0-methylglucose is a glucose analogue which is transported across the muscle cell membrane, but is not further metabolized, these data indicate that high concentrations of hIAPP affect the glucose transport process.

An inhibitory effect of 10 and $100 \mathrm{nmol} / \mathrm{l}$ of rat IAPP (rIAPP) on insulin-stimulated 2-deoxyglucose transport has been observed in studies using incubated soleus muscles [8]. 2-deoxyglucose is a glucose analogue which is transported over the cell membrane, phosphorylated by hexokinase, but is not further metabolized. In the latter study, 3-0-methylglucose transport was also assessed, but no effect of rIAPP in the $1-100 \mathrm{nmol} / \mathrm{l}$ range was evident. Taken together the authors concluded that rIAPP inhibits the phosphorylation of glucose at the hexokinase step. In the presence of a considerably higher concentration of IAPP $(1 \mu \mathrm{mol} / \mathrm{l})$, a $60 \%$ inhibition of insulin-stimulated 2deoxyglucose transport was demonstrated in an isolated rat diaphragm preparation [9]. The prior investigations conflict with another recent study which reported that $10 \mathrm{nmol} / \mathrm{l}$ of synthetic hIAPP had no effect on insulinstimulated rates of 2-deoxyglucose transport in rat soleus muscles [10]. The apparent discrepancies between our results, demonstrating an inhibitory effect of hIAPP on insulin-stimulated 3-0-methylglucose transport in human skeletal muscle, and the results of others $[8,10]$, utilizing rat soleus muscle preparations are unclear. One primary explanation would be related to species differences. The glucose transport rate in isolated human skeletal muscle strips as reported here, and by others $[12,20]$ is considerably lower in basal as well as insulin-stimulated states when compared to values reported for isolated rat skeletal muscle $[14,21,22]$. Similarly, the number of glucose transporters in human skeletal muscle is considerably lower when compared to rat soleus muscle (Zierath and Wallberg-Henriksson, unpublished observation). Thus, human skeletal muscle, with a lower transport rate and quantitatively fewer transporters, may have an increased sensitivity to IAPP when compared to rat skeletal muscle.

However, it is plausible that the conflicting results presented in the literature may be attributed to a spontaneous inactivation of IAPP by deposition into amyloid fibrils. We attempted to avoid this by dissolving and diluting the peptide immediately before addition to the muscle strip media. Other possible considerations would be methodological differences of the muscle preparations, incubation procedure or purity of the IAPP. Since these 
factors may play a critical role in the experimental milieu, further studies are necessary to clarify the influence of these components.

One possible mechanism for the inhibitory effect of hIAPP on the muscle glucose transport step could be a blocking, or an alteration of the binding of insulin to its receptor. To test this hypothesis, we stimulated glucose transport with a phorbol ester. The tumour-promoting phorbol ester, phorbol myristate acetate, has many insulin-like effects [23, 24], including stimulation of glucose transport $[21,25,26]$. The effect of PMA on cellular glucose uptake is reported to be linked with its activation of protein kinase C [19]. The stimulatory effect of PMA on glucose transport was totally abolished when muscles were exposed to $10 \mathrm{nmol} / \mathrm{l}$ of hIAPP, suggesting that the effect of hIAPP on the glucose transport process occurs at a step distal to the insulin-binding step.

In man, measurements of circulating concentrations of hIAPP, measured by radioimmunoassay techniques, have revealed that the physiological concentration of hIAPP is in the range of 1-10 pmol/1 [27-29]. Observed effects of hIAPP and rIAPP on glycogen levels $[4,5,8,10]$ and on rates of glucose transport [8] have been demonstrated using pharmacological concentrations (1-100 nmol/l). However, IAPP has been suggested to be a contributing factor in the development of skeletal muscle insulin resistance in Type 2 diabetic subjects $[4,5]$. In our study, 3-0methylglucose transport was unaltered when physiological concentrations of hIAPP were tested. Thus, our data indicate that hIAPP may not play a role in the development of peripheral insulin resistance characteristic of Type 2 diabetes.

Decreased rat skeletal muscle glycogen content following IAPP exposure is well documented $[4,5,8,10]$. Several reports suggest that glycogen degradation in the presence of IAPP is due to an inhibition of the glycogen synthesis step $[4,5,8]$. Yet one group has put forth evidence suggesting the possibility of an increased glycogenolysis to account for the glycogen degradation [8]. Results from a recent report utilizing the euglycaemic insulin-clamp technique to study glucose utilization in rat peripheral tissue demonstrates that hIAPP infusion decreases muscle glycogen synthesis [30]. The authors suggested that the observed inhibitory effect of hIAPP on skeletal muscle metabolism resulted from an increase in muscle glucose 6-phosphate levels and glycolysis, which in turn inhibit glucose transport.

In the present investigation, we were interested in examining the effects of hIAPP on the glucose transport step independent of any alteration in the glycogen level. Therefore, we used a glucose-free medium during the in vitro muscle incubations. With this protocol, glycogen and lactate levels were unaltered during insulin- or PMAstimulation. Furthermore, hIAPP did not affect the glycogen or lactate concentrations in the muscle strips. Thus, it was possible to differentiate between a direct effect of hIAPP on the glucose transport step and a secondary effect of the peptide on the glucose transport process by feedback regulation from changes in glycogen and glucose 6-phosphate levels [22,30-32]. Since glycogen and lactate concentrations were not changed, our results, taken together with previously published reports, indicate that hIAPP exerts an effect on the glucose transport step in addition to inhibiting glycogen synthesis $[4,5,30]$.

We have utilized a technique which has recently been developed for in vitro incubation of human skeletal muscle strips [12]. Tissues obtained and incubated using this technique have been found to maintain adequate concentrations of high energy phosphate, when compared to directly frozen muscle biopsies $[12,20]$. In addition, the muscle strips have been demonstrated to maintain an intact ultrastructure $[12,33]$. We have augmented this technique by obtaining muscle specimens with an open muscle biopsy technique, thus avoiding general anaesthesia and major surgical trauma. Although ATP and PCr levels decreased in the incubated muscle strips, the values are well within the normal range of a healthy muscle [34] and correspond with previously reported measurements using this preparation $[12,30,33]$. In addition, the lactate dehydrogenase levels of the muscle strips remained low during the incubation period, indicating no significant tissue damage.

In conclusion, pharmacological concentrations of hIAPP inhibit insulin- as well as phorbol ester-stimulated increases in glucose transport in incubated human skeletal muscle. However, physiological concentrations of hIAPP have no inhibitory effect on the rate of insulin-stimulated glucose transport. These results suggest that pharmacological levels of hIAPP inhibit glucose transport at a point distal to the insulin binding process.

Acknowledgements. We thank Ms. H. Tetzlaff for her valuable technical assistance. This study was supported by grants from the Swedish Medical Research Council (5117 and 5941), the Nordisk Insulin Fund, the Swedish Diabetes Association, the Wibergs Fund, the Thurings Fund for Medical Research, and from Novo-Nordisk AB.

\section{References}

1. Westermark P, Wilander E (1978) The influence of amyloid deposits on the islet volume in maturity onset diabetes mellitus. Diabetologia 15: 417-421

2. Westermark P, Wernstedt C, Wilander E, Hayden DW, O'Brien TD, Johnson KH (1987) Amyloid fibrils in human insulinoma and islets of Langerhans of the diabetic cat are derived from a neuropeptide-like protein also present in normal islet cells. Proc Natl Acad Sci USA 84: 3881-3885

3. Cooper GJS, Willis AC, Clark A, Turner RC, Sim RB, Reid KBM (1987) Purification and characterization of a peptide from amyloid-rich pancreases of type 2 diabetic patients. Proc Natl Acad Sci USA 84: 8628-8632

4. Cooper GIS, Leighton B, Dimitriadis BD et al. (1988) Amylin found in amyloid deposits in human type 2 diabetes mellitus may be a hormone that regulates glycogen metabolism in skeletal muscle. Proc Natl Acad Sci USA 85: 7763-7766

5. Leighton B, Cooper GJS (1988) Pancreatic amylin and calcitonin gene-related peptide cause resistance to insulin in skeletal muscle in vitro. Nature (Lond) 335: 632-635

6. Molina JM, Cooper GJS, Leighton B, Olefsky JM (1990) Induction of insulin resistance in vivo by amylin and calcitonin gene-related peptide. Diabetes 39:260-265

7. Sowa R, Sanke T, Hirayama J et al. (1990) Islet amyloid polypeptide amide causes peripheral insulin resistance in vivo in dogs. Diabetologia 33: 118-120

8. Young DA, Deems RO, Deacon RW, McIntosh RH, Foley JE (1990) Effects of amylin on glucose metabolism and glycogeno- 
lysis in vivo and in vitro. Am J Physiol 259 (Endocrinol Metab 22): E457-E461

9. Hothersall JS, Muirhead RP, Wimalawansa S (1990) The effect of amylin and calcitonin gene-related peptide on insulin-stimulated glucose transport in the diaphram. Biochem Biophys Res Comm 169: 451-454

10. Leighton B, Foot E (1990) The effects of amylin on carbohydrate metabolism in skeletal muscle in vitro and in vivo. Biochem J 269: 19-23

11. Bretherton-Watt D, Gilbey SG, Ghatei MA, Beacham J, Bloom SR (1990) Failure to establish islet amyloid polypeptide (amylin) as a circulating beta cell inhibiting hormone in man. Diabetologia 33: 115-117

12. Dohm GL, Tapscott EB, Pories WJ et al. (1988) An in vitro human muscle preparation suitable for metabolic studies. J Clin Invest 82: 486-494

13. Krebs HA, Henseleit K (1932) Untersuchungen über die Harnstoffbildung im Tierkörper. Hoppe-Seyler's Z Physiol Chem 210: 33-66

14. Wallberg-Henriksson H, Zetan N, Henriksson J (1987) Reversibility of decreased insulin-stimulated glucose transport capacity in diabetic muscle with in vitro incubation. J Biol Chem 262: 7665-7671

15. Merrifield RB (1963) Solid phase peptide synthesis. I. The synthesis of a tetrapeptide. J Am Chem Soc 85: 2149-2154

16. Sundqvist B, MacFarlane RD (1985) ${ }^{252}$ Cf-Plasma desorption mass spectrometry. Mass Spectrom Rev 4: 421-460

17. Lowry OH, Passonneau JV (1972) A flexible system of enzymatic analysis. Academic Press, New York

18. Keiding R (1974) Recommended methods for the determination of four enzymes in blood. Scand J Clin Lab Invest 33: 291-306

19. Nishizuka Y, Takai Y, Kishimoto A, Kikkawa U, Kaibuchi K (1984) Phospholipid turnover in hormone action. Rect Prog Horm Res 40: 301-345

20. Andréasson K, Galuska D, Thörne A, Sonnenfeld T, WallbergHenriksson H (1991) Decreased insulin-stimulated 3-0-methylglucose transport in in vitro incubated muscle strips from type II diabetic subjects. Acta Physiol Scan 142: 255-260

21. Henriksen EJ, Rodnick KJ, Holloszy JO (1989) Activation of glucose transport in skeletal muscle by phospholipase $\mathrm{C}$ and phorbol ester. J Biol Chem 264: 21536-21543

22. Wallberg-Henriksson H (1987) Glucose transport into skeletal muscle: influence of contractile activity, insulin, catecholamines and diabetes mellitus. Acta Physiol Scan [Suppl] 564: 1-80

23. Van de Werve G, Proietto J, Jeanrenaud B (1985) Tumour-promoting phorbol esters increase basal and inhibit insulin-stimulated lipogenesis in rat adipocytes without decreasing insulin binding. Biochem J 225: 523-527

24. Kirsch D, Obermaier B, Häring HU (1985) Phorbolesters enhance basal D-glucose transport but inhibit insulin stimulation of
D-glucose transport and insulin binding in isolated rat adipocytes. Biochem Biophys Res Comm 128: 824-832

25. Farese RV, Standaert ML, Barnes DE, Davis JS, Pollet RJ (1985) Phorbol ester provokes insulin-like effects on glucose transport, amino acid uptake, and pyruvate dehydrogenase activity in BC3H-1 cultured myocytes. Endocrinology 116: 2650-2655

26. Cherqui G, Caron M, Wicek D, Lascols O, Capeau J, Picard J (1986) Insulin stimulation of glucose metabolism in rat adipocytes: possible implication of protein kinase C. Endocrinology 118: $1759-1769$

27. Butler PC, Chou J, Bradford Carter W et al. (1990) Effects of meal ingestion on plasma amylin concentration in NIDDM and nondiabetic humans. Diabetes 39: 752-756

28. Steiner DF, Ohagi S, Nagamatsu S, Bell GI, Nishi M (1991) Is islet amyloid polypeptide a significant factor in pathogenesis or pathophysiology of diabetes? Diabetes 40:305-309

29. Nakazato M, Asai J, Kangawa K, Matsukura S, Matsuo H (1989) Establishment of radioimmunoassay for human islet amyloid polypeptide and its tissue content and plasma concentration. Biochem Biophys Res Commun 164: 394-399

30. Frontoni S, Choi SB, Banduch D, Rossetti L (1991) In vivo insulin resistance induced by amylin primarily through inhibition of insulin-stimulated glycogen synthesis in skeletal muscle. Diabetes 40: 568-573

31. Fell RD, Terblanche SE, Ivy JL, Young JC, Holloszy JO (1982) Effect of muscle glycogen content on glucose uptake following exercise. J Appl Physiol (Respirat Environ Exercise Physiol) 52: 434-437

32. Foley JE, Huecksteadt TP (1984) Glucose 6-phosphate effects on deoxyglucose, glucose, and methylglucose transport in rat adipocytes. Evidence for intracellular regulation of sugar transport by glucose metabolites. Biochem. Biophys Acta 805: 313316

33. Argyraki M, Wright PD, Venables CW, Proud G, Taylor R (1989) In vitro study of human skeletal muscle strips: Effect of nonesterified fatty acid supply on glucose storage. Metabolism 38: 1183-1187

34. Newsholme EA, Leech AR (1983) Biochemistry for the medical sciences. John Wiley, Chichester New York

Received: 31 May 1991

and in revised form: 12 August 1991

Dr. H. Wallberg-Henriksson

Department of Clinical Physiology

Karolinska Hospital

Box 60500

S-10401 Stockholm

Sweden 